\title{
RAINFALL PROBABILITY ANALYSIS FOR CROP PLANNING IN CUTTACK SADAR BLOCK OF CUTTACK DISTRICT OF ODISHA,INDIA
}

\author{
S. Jethy*, Pattnaik, S.* , G.P.Sahoo*, S.Mishra*, R.Subudhi* \& Dr. C.R.Subudhi **, \\ ** Professor, CAET, OUAT, Bhubaneswar-751003, Odisha \\ **Student, CAET, OUAT, Bhubaneswar-751003
}

\begin{abstract}
This study was under taken in the U.G. work in the Dept. Of SWCE, CAET, OUAT, Bhubaneswar during the year 2020. Cuttack Sadar has latitude of $20^{\circ} 28^{\prime} 32^{\prime \prime} \mathrm{N}$ and longitude of $85^{\circ} 51^{\prime}$ 5328 " E. The average rainfall at Kalahandi district is around $1440 \mathrm{~mm}$, though it receives high amount rainfall but most of the rainfall occurred during kharif. So most of the crops get low yield due to improper crop planning. Thus, this study is proposed to be undertaken with the following objective: Probability analysis of annual, seasonal and monthly rainfall data of Cuttack block of Cuttack district. So, rainfall data were collected from OUAT, Agril Meteorology Dept. from 2001 to 2017(17 years) monthly, seasonal and annual rainfall were analyzed. Probability analysis have been made and equations were fitted to different distributions and best fitted equations were tested. Monthly, Annual and seasonal probability analysis of rainfall data shows the probability rainfall distribution of Cuttack Sadar block of Cuttack district in different months, years and seasons. It is observed that rainfall during June to Sep is more than $100 \mathrm{~mm}$ and cropping pattern like paddy ( 110 days) may be followed by black gram is suitable to this region. Also, if the kharif rain can be harvested and it can be reused for another rabi crop by using sprinkler or drip irrigation, which will give benefit to the farmers.
\end{abstract}

Key words- Rainfall ; probability analysis ; crop planning, 


\section{INTRODUCTION}

Cuttack district has altitude of $28 \mathrm{~m}$ above mean sea level. Cuttack district has latitude of $20^{\circ} 28^{\prime} 32^{\prime \prime} \mathrm{N}$ and longitude of $85^{\circ} 51^{\prime} 5328^{\prime \prime} \mathrm{E}$. The average rainfall at Cuttack district is $1440 \mathrm{~mm}$, most of the rainfall occurred during kharif. Thus, this study is proposed to be undertaken with the following objective: Probability analysis of annual, seasonal and monthly rainfall data of Cuttack Sadar block of Cuttack district.

Thom (1966) employed mixed gamma probability distribution for describing skewed rainfall data and employed approximate solution to nonlinear equations obtained by differentiating log likelihood function with respect to the parameters of the distribution. Subsequently, this methodology along with variance ratio test as a goodness- of-fit has been widely employed Kar et. al (2004), Jat et. al (2006), Senapati et. al (2009) applied incomplete gamma probability distribution for rainfall analysis. In addition to gamma probability distribution, other twoparameter probability distributions (normal, log-normal, Weibull, smallest and largest extreme value), and three-parameter probability distributions (log-normal, gamma, log-logistic and Weibull) have been widely used for studying flood frequency, drought analysis and rainfall probability analysis ( Senapati et. al.2009); Panigrahi and Panda (2001), \& (Subudhi, C.R. et.al.2019)
Gumbel (1954), \& Chow (1964) have applied gamma distribution with two and three parameter, Pearson type-III, extreme value, binomial and Poisson distribution to hydrological data.

\section{Materials and methods}

The data were collected from District Collector's Office, Kalahandi district for this study. Rainfall data for 17 years from 2001 to 2017 are collected for the presented study to make rainfall forecasting through different methods

\section{Probability Distribution Functions}

For seasonal rainfall analysis of Kalahandi district, three seasons- kharif (June-September), rabi (October to January) and summer (February to May) are considered.

The data is fed into the Excel spreadsheet, where it is arranged in a chronological order and the Weibull plotting position formula is then applied. The Weibull plotting position formula is given by

$$
p=\frac{m}{N+1}
$$

where $m=$ rank number

$$
N=\text { number } \text { of } y e a r s
$$

The recurrence interval is given by

$$
T=\frac{1}{p}=\frac{N+1}{m}
$$

The values are then subjected to various probability distribution functions namely- 
normal, log-normal (2-parameter), lognormal (3-parameter), gamma, generalized extreme value, Weibull, generalized Pareto distribution, Pearson, log-Pearson type-III and Gumbel distribution. Some of the probability distribution functions are described as follows:

Normal Distribution:-

The probability density is

$p(x)=(1 / \sigma \sqrt{2 \pi}) e^{-(x-\mu)^{2} / 2 \sigma^{2}}$

where $\mathrm{x}$ is the variate, $\mu$ is the mean value of variate and $\sigma$ is the standard deviation. In this distribution, the mean, mode and median are the same. The cumulative probability of a value being equal to or less than $x$ is

$p(x \leq)=1 / \sigma \sqrt{2 \pi} \int_{-\infty}^{x} e^{-(x-\mu)^{2} / 2 \sigma^{x}} d x$

This represents the area under the curve between the variates of $-\infty$ and $x$.

Log-normal (2-parameter) Distribution:-

The probability density is

$p(x)=\left(1 / \sigma_{y} e^{y} \sqrt{2 \pi}\right) e^{-\left(y-\mu_{y}\right)^{2} / 2 \sigma_{y}}$

where $\mathrm{y}=\ln \mathrm{x}$, where $\mathrm{x}$ is the variate, $\mu_{y}$ is the mean of $y$ and $\sigma_{y}$ is the standard deviation of $y$.

Log-normal (3-parameter) distribution:-

A random variable $X$ is said to have threeparameter log-normal probability distribution if its probability density function (pdf) is given by:

$f(x)=\left\{\frac{1}{(x-\lambda) \sigma \sqrt{2 \pi}} \exp \left\{-\frac{1}{2}\left(\frac{\log (x-\lambda)-\mu}{\sigma}\right)^{2}\right\}, \lambda<\right.$

where $\mu, \sigma$ and $\lambda$ are known as location, scale and threshold parameters, respectively.

Pearson Distribution:-

The general and basic equation to define the probability density of a Pearson distribution

$p(x)=e \int_{-\infty}^{x} \frac{a+x}{b_{0}+b_{1} x+b_{2} x^{2}} d x$

where $a, b_{0}, b_{1}$ and $b_{2}$ are constants.

The criteria for determining types of distribution are $\beta_{1}, \beta_{2}$ and $k$ where

$\beta_{1}=\frac{\mu_{3}^{2}}{\mu_{2}^{3}}$

$\beta_{2}=\frac{\mu_{4}}{\mu_{2}^{2}}$

$k=\frac{\beta_{1}\left(\beta_{2}+3\right)^{2}}{4\left(4 \beta_{2}-3 \beta_{1}\right)\left(2 \beta_{2}-3 \beta_{1}-6\right)}$

Where $\mu_{2}, \mu_{3}$ and $\mu_{4}$ are second, third and fourth moments about the mean.

Log-Pearson Type III Distribution:-

In this the variate is first transformed into logarithmic form (base 10) and the transformed data is then analyzed. If $X$ is 2020 November Edition | www.jbino.com | Innovative Association 
the variate of a random hydrologic series, then the series of $Z$ variates where

$z=\log x$

are first obtained. For this z series, for any recurrence interval $T$ and the coefficient of skew $C_{s^{y}}$

$\sigma_{z}=$ standard deviation of the $Z$ variate sample

$$
=\sqrt{\sum(z-\bar{z})^{2} /(N-1)}
$$

And $C_{s}=$ coefficient of skew of variate $Z$

$$
=\frac{N \sum(z-\bar{z})^{\mathrm{g}}}{(N-1)(N-2) \sigma_{z}^{\mathrm{a}}}
$$

$\bar{z}=$ mean of $z$ values

$N=$ sample size $=$ number of $y e a r s$ of record

Generalized Pareto Distribution:-

The family of generalized Pareto distributions (GPD) has three parameters $\mu, \sigma$ and $\xi$.

The cumulative distribution function is

$F_{(\xi, \mu, \sigma)}(x)=\left\{\begin{array}{cc}1-\left(1+\frac{\xi(x-\mu)}{\sigma}\right)^{\frac{-1}{\xi}} \text { for } \xi \neq 0 \\ 1-\exp \left(-\frac{x-\mu}{\sigma}\right) & \text { for } \xi=0\end{array}\right\}$ for $x \geq \mu$ when $\xi \geq 0$ and $x \leq \mu-\frac{\sigma}{\xi}$ when $\xi<0$,where $\mu \in \mathbb{R}$ is the location parameter, $\sigma>0$ the scale parameter and $\xi \in \mathbb{R}$ the shape parameter.

The probability density function is

$f_{(\xi, \mu, \sigma)}(x)=\frac{1}{\sigma}\left(1+\frac{\xi(x-\mu)}{\sigma}\right)^{\left(-\frac{1}{\xi}-1\right)}$

Or

$f_{(\xi, \mu, \sigma)}(x)=\frac{\sigma^{\frac{1}{\xi}}}{(\sigma+\xi(x-\mu))^{\left(\frac{1}{\xi}+1\right)}}$

again, for $x \geq \mu$, and $x \leq \mu-\frac{\sigma}{\xi}$ when $\xi<0$

\section{Result and discussion}

The various parameters like mean, standard deviation, RMSE value were obtained and noted for different distributions. The rainfall at $90 \%, 75 \%, 50 \%, 25 \%$ and $10 \%$ probability levels are determined. The distribution "best" fitted to the data is noted down in a tabulated form in Table 1. 
Table 1 Rainfall analysis of Cuttack Sadar Block at different probability levels for different months and seasons.

\begin{tabular}{|c|c|c|c|c|c|c|c|}
\hline \multirow[t]{2}{*}{ Months } & \multirow{2}{*}{$\begin{array}{l}\text { Best-fit } \\
\text { Distribution }\end{array}$} & \multirow{2}{*}{$\begin{array}{l}\text { RMSE } \\
\text { Value }\end{array}$} & \multicolumn{5}{|c|}{ Rainfall at probability levels } \\
\hline & & & $90 \%$ & $70 \%$ & $50 \%$ & $20 \%$ & $10 \%$ \\
\hline January & General Pareto & 0.051 & - & - & - & 37.9 & 64.2 \\
\hline February & $\begin{array}{l}\text { Generalised } \\
\text { Extreme Value }\end{array}$ & 0.054 & - & - & - & 37.8 & 58.9 \\
\hline March & Log Pearson & 0.071 & - & - & - & 15.8 & 52.4 \\
\hline April & Gamma & 0.083 & - & - & - & 26.0 & 65.9 \\
\hline May & General Pareto & 0.066 & - & - & - & 26.0 & 56.6 \\
\hline June & General Pareto & 0.045 & 46.7 & 92.6 & 148.0 & 268.9 & 337.4 \\
\hline July & $\begin{array}{l}\text { Generalised } \\
\text { Extreme Value }\end{array}$ & 0.027 & 171.2 & 249.8 & 320.7 & 478.8 & 593.5 \\
\hline August & $\begin{array}{l}\text { Gumbel } \\
\text { maximum }\end{array}$ & 0.051 & 152.1 & 247.9 & 329.5 & 497.0 & 607.9 \\
\hline September & Normal & 0.062 & 117.7 & 261.3 & 360.7 & 520.4 & 603.9 \\
\hline October & Log Pearson & 0.048 & 174.1 & 246.8 & 317.2 & 480.2 & 599.0 \\
\hline November & General Pareto & 0.04144 & - & - & - & 31.7 & 52.0 \\
\hline December & General Pareto & 0.08016 & -- & - & -- & 4.1 & 24.8 \\
\hline Annual & $\begin{array}{l}\text { Gumbel } \\
\text { maximum }\end{array}$ & 0.05234 & 2953.1 & 3196.1 & 3402.9 & 3827.6 & 4108.8 \\
\hline $\begin{array}{l}\text { Kharif } \\
\text { (June-Sept) }\end{array}$ & Gamma & 0.06218 & 673.2 & 924.4 & 1131.6 & 1525.5 & 1763.0 \\
\hline $\begin{array}{l}\text { Rabi } \\
\text { (Oct-Jan) }\end{array}$ & Lognormal & 0.02856 & 36.3 & 74.9 & 123.6 & 276.4 & 421.1 \\
\hline $\begin{array}{l}\text { Summer } \\
\text { (Feb-May) }\end{array}$ & EV type III & 0.04541 & 1.4 & 61.8 & 102.1 & 170.3 & 207.2 \\
\hline
\end{tabular}


In the present study, the parameters of distribution for the different distributions have been estimated by FLOOD frequency analysis software. The rainfall data is the input to the software programme. The best fitted distribution of different month and seasons and annual were presented in Table 1.During Kharif at 50\% probability level, the rainfall is $1131.6 \mathrm{~mm}$ where as only $123.6 \mathrm{~mm}$ and $102.1 \mathrm{~mm}$ was received during rabi and summer respectively.

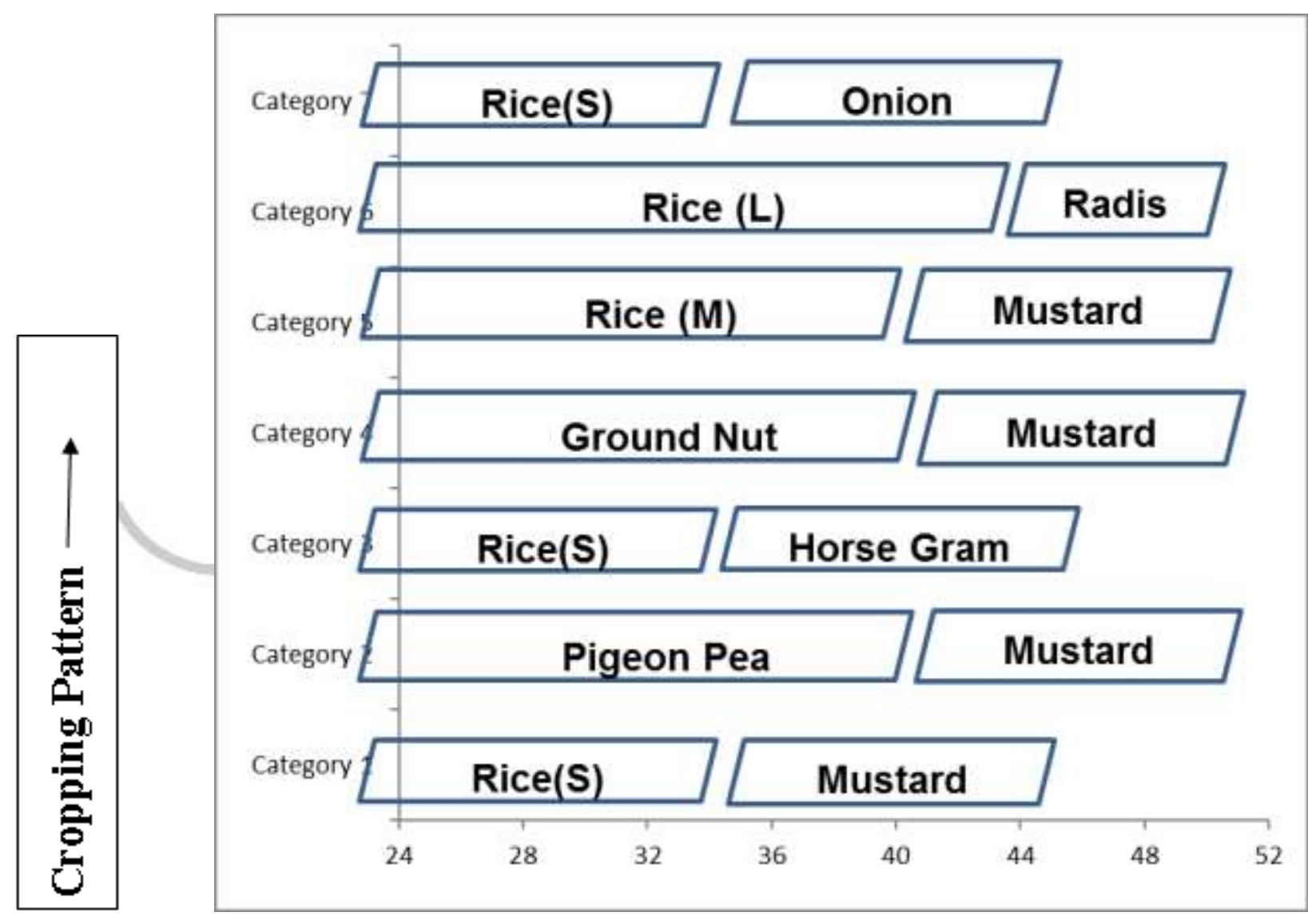

\section{MVEKS (SM WN)}

- Fig 1 Different cropping patterns for Cuttack Sadar block of Cuttack district 
In the present study, the parameters of distribution for the different distributions have been estimated by FLOOD-flood frequency analysis software. The rainfall data is the input to the software programme. The best fitted distribution of different month and season and annual were presented in Table 1. During Kharif at $50 \%$ probability level, the rainfall is 1131.6 $\mathrm{mm}$ where as only $123.6 \mathrm{~mm}$ and $102.1 \mathrm{~mm}$ was received during rabi and summer respectively.

In the present study, the parameters of distribution for the different distributions have been estimated by FLOOD-flood frequency analysis software. The rainfall data is the input to the software programme. The best fitted distribution of different month and season and annual were presented in Table 1. so water harvesting structures may be made to grow crops during rabi and summer to utilize the water from the water harvesting structures to increase the cropping intensity of the area. It is also observed that at $75 \%$ probability level the June, July, Aug and Sept received more than $100 \mathrm{~mm}$, so farmers of these area can grow crops in upland areas suitably paddy can be grown followed by any rabi crop in rabi season like mustard or kulthi in upland areas. It is observed that September month gets highest amount of rainfall compared to other months. Fig 1 shows the different cropping pattern in Cuttack Sadar block of Cuttack district as per the rainfall available in different weeks.

\section{Conclusion}

Forecasting of rainfall is essential for proper planning of crop production. About $70 \%$ of cultivable land of Odisha depends on rainfall for crop production. Prediction of rainfall in advance helps to accomplish the agricultural operations in time. It can be concluded that, excess runoff should be harvested for irrigating post-monsoon crops. It becomes highly necessary to provide the farmers with high-yielding variety of crops and such varieties which require less water and are early-maturing inCuttack district of of Odisha. It is also observed that at $70 \%$ probability level the June, July, Aug and Sept received more than $100 \mathrm{~mm}$, so farmers of these area can grow crops in upland areas suitably paddy can be grown followed by any rabi crop in rabi season like mustard or kulthi in upland areas. It is observed that September month gets highest amount of rainfall compared to other months. Different cropping pattern selected may be may be practiced in this district.

\section{References}

Biswas, B.C. 1990. Forecasting for agricultural application. Mausam. $41(2): 329-334$.

Chow, V.T. (1964) Hand book of Applied Hydrology McGraw Hill Book Co., NewYork.8-28

Das, M.K. 1992. Analysis of agrometerological data of Bhubaneswar for crop planning. M.Tech. thesis. C.A.E.T., OUAT. 
Gumbel, E.J. 1954. Statistical theory of droughts. Proceedings of ASCE. 80(439):119

Gumbel, E.J. 1958. Statistics of extremes. Columbia University Press, New York.

Harshfield, D.M. and Kohlar, M.A. 1960. An empirical appraisal of the Gumbel extreme procedure. J. of Geophysics Research, 65:1737-1746.

Kar, G., Singh, R., Verma, H.N. 2004. Alternative cropping strategies for assured and efficient crop production in upland rain fed rice areas of eastern India based on rainfall analysis. 67: 47-62.

Jat, M. L., Singh, R. V., Balyan, J. K., Jain, L.K., Sharma, R.K. 2006. Analysis of weekly rainfall for Sorghum based crop planning in Udaipur region. Indian J. Dry land agric. Res. \& Dev., $21(2): 114-122$.

Panigrahi, B. \& Panda, S.N. (2001) Analysis of weekly rainfall for crop planning in rainfed region. Journal of Agricultural Engineering, 38(4):47-57.

Panigrahi, B., 1998. Probability analysis of short duration rainfall for crop planning in coastal Orissa. Indian J. Soil Cons., 26(2): 178-182.

Reddy, S.R. 1999. Principles of Agronomy. $1^{\text {st }}$ edition. Kalyani publication.

Sadhab, P. 2002. Study of rainfall distributions and determination of drainage coefficient: A case study for coastal belt of Orissa. M. Tech. thesis. C. A. E. T., OUAT.

Senapati, S. C., Sahu, A.P., Sharma, S.D. 2009. Analysis of meteorological events for crop planning in rain fed uplands. Indian J. Soil Cons., $37(2): 85-90$

Sharda, V.N. and Das, P.K. 2005. Modeling weekly rainfall data for crop planning in a sub-humid climate of India. Agricultural Water Management,76:120-138

Subramanya, K. 1990. Engineering Hydrology. 23rd reprint. Tata Mc-graw Hill Publishing Company Ltd.

Subudhi, C.R. 2007. Probability analysis for prediction of annual maximum daily rainfall of Chakapada block of Kandhamal district of Orissa. Indian J. Soil Cons., 35 (1):84-85.

Thom, H.C.S.1966. Some methods of climatological analysis. WMO Tech. Note. No. 81.

Weibull, W. 1951. A statistical distribution functions of wide applicability. J. Appl. Mech.-Tran. ASME, 18(3):293-297.

Subudhi, C.R., Suryavansi, S. \& Jena, N.(2019) Rainfall probability analysis for crop planning in Anugul block of Anugul district of Hirakud command area of Odisha,India. International Journal of Humanities and Social Sciences.8(3): 49-54.

Subudhi, C.R., Suryavansi, S., Jena, N. Subudhi, R.(2019) Rainfall analysis for crop 2020 November Edition | www.jbino.com | Innovative Association 
planning in Puri district of Odisha. Journal of Agriculture and Forest Meteorology Research. 3(2):325-328.

Subudhi, C.R., Suryavansi, S., Jena, N.; Subudhi, R.(2019) "Rainfall analysis for crop planning in Bargarh district of Odisha." Biometrix and Biostatistics International Journal. 8(5):178-182.

Subudhi, C.R., Jena, N.;Suryavansi, S., Subudhi R.(2019) "Rainfall probability analysis for crop planning in Rayagada district of Odisha.India" International Journal of Hydrology. 3(6):507-511.

Subudhi, C.R., Jena, N.; Suryavansi, S., Subudhi R.(2019) "Rainfall probability analysis for crop planning in Sambalpur district of Odisha.India" Biometrix and
Biostatistics International Journal. 8(6):217221.

Subudhi, C.R., Suryavansi, S., Jena, N.; (2019) "Rainfall probability analysis for crop planning in Ganjam district of Hirakud command area of Odisha.India" Scientific Forefront Journals, 2(2):1-6.

Subudhi, C.R., Jena, N.; Suryavansi, S., Subudhi R.(2019) "Rainfall probability analysis for crop planning in Jagatsingpur district of Odisha.India" International Journal of Molecular Biology and Biochemistry.1 (1):18-21.

Subudhi, C.R., Suryavansi, S., Jena, N. Subudhi R.(2019) "Rainfall probability analysis for crop planning in Deogarh district of Odisha.India" South Asian J. Food Techology Environ.5(2):840-845. 